\title{
THE AVAILABILITY OF TOBACCO CESSATION PRODUCTS AND SERVICES IN COMMUNITY PHARMACIES IN TÂRGU MUREŞ, ROMANIA
}

\author{
RAREȘ-DANIEL LUCA, ANDREEA NĂDĂȘAN, ASTRID JERCA, PAULA-VIORICA \\ ALEXANDER, LORÁND FERENCZ, ZOLTÁN ÁBRÁM, VALENTIN NĂDĂȘAN*
}

“George Emil Palade” University of Medicine, Pharmacy, Science, and Technology, 38 Gheorghe Marinescu Street, 540139, Târgu Mureș, Romania

*corresponding author: valentin.nadasan@umfst.ro

Manuscript received: February 2020

\begin{abstract}
The study aimed to assess the availability of tobacco cessation products and services in community pharmacies in Târgu Mureș, Romania. The study included a representative sample of 47 pharmacies. Data were collected using the simulated client method by four trained assessors following a common protocol. The most recommended medication was nicotine replacement therapy; either as gum (80\%), patch (70\%) or sublingual spray (51\%). Varenicline was recommended in $8.5 \%$ of the pharmacies. A few pharmacists also recommended plant-based extracts. While posology was explained in $80 \%$ of the pharmacies, warnings about the adverse effects were presented in only $8.5 \%$, and withdrawal symptoms were evaluated in only $19.1 \%$. Referral to a medical professional or stop-smoking centre was given by $70 \%$ of pharmacists. The study identified strengths and weaknesses that will be useful in developing a training program aimed to implement a quit-smoking intervention in the community pharmacies in Târgu Mureș, Romania.
\end{abstract}

\section{Rezumat}

Obiectivul studiului a fost evaluarea disponibilităţii produselor şi serviciilor de renunţare la fumat în farmaciile comunitare din Târgu Mureș, România. Studiul a inclus un eșantion reprezentativ de 47 de farmacii. Datele au fost colectate prin metoda „client misterios” de către patru evaluatori instruiți, care au respectat un protocol identic. Medicația cel mai frecvent recomandată a fost cea de substituție nicotinică, sub formă de gumă (80\%), plasture (70\%) sau spray sublingual (51\%). Vareniclina a fost recomandată în 8,5\% dintre farmacii. Câțiva farmaciști au recomandat și extracte din plante. Posologia a fost explicată în $80 \%$ și efectele adverse doar în 8,5\% dintre farmacii. Simptomele de sevraj au fost evaluate în numai 19,1\% din cazuri. Un procent de $70 \%$ dintre farmaciști au îndrumat fumătorii către un specialist/centru stop-fumat. Studiul a identificat puncte tari și slabe care vor fi utile în dezvoltarea unui program de instruire în vederea implementării unei intervenții pentru renunțare la fumat în farmaciile comunitare din Târgu Mureș, România.

Keywords: tobacco cessation, nicotine replacement therapy, community pharmacies, simulated client

\section{Introduction}

There is a large consensus among specialists that tobacco dependence treatment including behavioural support and medication is a cost-effective healthcare intervention for smoking cessation $[3,6,7]$. The World Health Organization Framework Convention on Tobacco Control encourages participant countries to create a sustainable infrastructure that offers affordable tobacco dependence treatment [13].

The community pharmacist is often the first medical professional that a patient encounters usually before even seeking help from a licensed doctor. There is evidence that community pharmacists can provide effective cessation assistance to people trying to stop smoking $[1,4]$. Nevertheless, their involvement and expertise in helping smokers to quit remain undocumented in Romania.
The purpose of the study was to evaluate the knowledge, attitude and involvement of the community pharmacists in smoking cessation support and the availability of medication for treating nicotine addiction in the community pharmacies in Târgu Mureș, Romania.

\section{Materials and Methods}

The research was designed as a cross-sectional, observational study. The protocol was approved by the ethics board of the "George E. Palade" University of Medicine, Pharmacy, Science, and Technology of Târgu Mureș, Romania (no. 56/02.04.2019).

A list of all the pharmacies in Târgu Mureș, Romania (97 in total) was obtained from the Mureș County College of Pharmacists. A representative sample of 47 pharmacies was randomly selected from the list, with a $95 \%$ confidence interval and a $10 \%$ margin of error. 
A protocol and on-location assessment scenario were developed to evaluate the availability of quitsmoking products and counselling. Data were collected using the simulated client method in April 2019, at various hours during the day from 11 a.m. to 9 p.m., by four medical students, properly trained beforehand. The profile for the simulated smoker was: $22-24$ years of age, smoker since high school, and showed signs of withdrawal after not smoking for a few hours (e.g. became irritable, anxious and unable to focus). The assessment protocol consisted of three sections: (A) Quit-smoking products; (B) Smoking cessation advice; (C) Referral to stop-smoking clinic. The detailed list of variables collected is presented in Table I. In all relevant situations, it was also recorded whether the information was offered spontaneously, on-demand or was not offered at all.

In order to improve data collection and eliminate sources of error, the information collected at the site of each pharmacy was recorded in an electronic database within five minutes after the completion of the evaluation. Absolute and relative frequencies were calculated for all variables.

Table I

Protocol of evaluation in pharmacies

Section A

Q1. What medicines or products were recommended?

\begin{tabular}{|l|c|l|}
\hline Q2. Was any proof of efficacy presented? (e.g. (a) medical studies; (b) examples of people who & Yes (please & No \\
\hline
\end{tabular} successfully quit; (c) other types of proof)

Q3. Was the mechanism of action presented? (e.g. nicotine substitution, withdrawal symptom reduction, reducing the urge to smoke)

Q4. Were dispensing and dosage presented? (e.g. oral, patch, chewing gum; 1/day, 3/day) Q5. Were the adverse effects presented?

Q6. Were you asked about allergies, heart disease, digestive disease, liver or kidney disease, epilepsy, pregnancy or lactation? (Acceptable alternative: the pharmacist mentions the precautions and contraindications.)

Q7. Were you asked whether you need the product for yourself or for somebody else?

Q8. Was any question about the withdrawal symptoms and their intensity asked? (e.g. nervousness, anxiety, depression, insomnia, other symptoms). Was any nicotine addiction test recommended? (e.g. Fagerstrom test).

Q9. Were you asked whether you previously used the recommended medication or any other medication?

Section B

Q10. Was any advice offered on any techniques, aside from medication, that could be beneficial in smoking cessation?

Q11. Were you suggested to try again at a later time to further discuss complementary advice?

Section C

Q12. Were you referred to a specialist, specialized clinic, counselling or information source regarding smoking cessation? (e.g. pulmonologist, tabaccologist, psychologist, local smoking cessation centre, associations, organizations, leaflets, websites, etc.)

\section{Results and Discussion}

Of the 47 total pharmacies, $44(93.6 \%)$ recommended at least one nicotine replacement products. The frequency of the recommended smoking cessation products is presented in Figure 1.

Smokers' positive feedback was mentioned in 15 locations (31.9\%) as evidence of medication's efficacy. None of the pharmacists mentioned research as proof of efficacy.

In 26 pharmacies $(55.3 \%)$ the client was given an explanation regarding how the recommended medication works. Twenty pharmacists ( $76.9 \%$ of the 26 locations) explained that the nicotine contained in the product replaces the nicotine released from the cigarette, 11 pharmacists $(55 \%)$ said that the therapy reduced the urge to smoke, and 3 pharmacists $(27.3 \%)$ informed the client that the treatment would diminish nicotine withdrawal symptoms.



Figure 1.

The frequency of smoking cessation products recommended in the community pharmacies in Târgu Mureș, Romania

Posology was explained in 38 locations (80.9\%), warnings about the adverse effects were given in 4 places $(8.5 \%)$, and information regarding contraindications 
of the pharmaceutical products was presented in 7 pharmacies $(14.9 \%)$.

In 14 pharmacies $(29.8 \%)$, the practitioner inquired who the therapy is needed for, in 9 cases $(19.1 \%)$, the client was asked about the intensity of the withdrawal symptoms, and in 10 cases (21.3\%), the person soliciting quit assistance was interrogated about previous therapy. Advice regarding quit strategies and techniques was given in 28 places $(59.6 \%)$. "Will power" was proposed in 17 locations $(60.7 \%)$, replacement of the tobacco habit and gestures in 12 cases $(42.9 \%)$, physical activity in 3 pharmacies $(10.7 \%)$, and other various techniques in 6 sites (21.4\%). These suggestions concerning quit techniques were offered proactively in 10 pharmacies $(21.3 \%)$, and upon request in 18 locations $(38.3 \%)$. In 19 pharmacies $(40.4 \%)$ the client received no guidance at all.

Referral to various specialists was made by 33 (70.2\%) pharmacists (Figure 2). The referral was made in a proactive manner by 7 pharmacists $(14.9 \%)$ and ondemand by 26 pharmacists $(55.3 \%)$. In 14 situations (29.8\%) the pharmacists expressed the idea that the help of a qualified smoking cessation specialist is not needed.

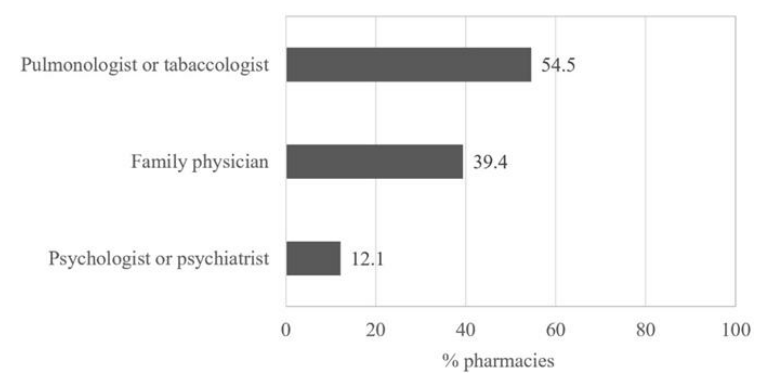

Figure 2.

Relative frequency of smoking cessation referrals made to various specialists in the community pharmacies in Târgu Mureș, Romania

Nicotine replacement products were recommended in almost all the pharmacies (93.6\%) very likely revealing a high familiarity of the pharmacists with this basic intervention for smoking cessation. The most frequently recommended nicotine replacement product was nicotine chewing gum $(80.9 \%)$, probably related to its affordability (in most drug-stores, one-piece costs less than one cigarette), its ease of use, and utility as an aid in replacing the smoking-associated routine. However, nicotine patches and nicotine mouth spray was also frequently suggested $(70.2 \%$ and $51.1 \%$ respectively). Apparently, product recommendation frequency was inversely related to its price.

The use of varenicline, a nicotine-free prescription medication acting as a nicotine receptor partial agonist with proven efficacy in increasing long-term abstinence among quitters $[2,5]$, was an uncommon therapeutic suggestion $(8.5 \%$ of the pharmacies). Varenicline used to be prescribed for free by pulmonologists within the National Stop-Smoking Program from 2007, but over the years progressively fewer smokers were able to access the program due to financial constraints and thus paid medication remained the only option available for interested smokers [10]. The significant cost of varenicline may explain why pharmacists seldom introduce it to their clients.

Although bupropion, the first non-nicotinic pharmacological therapy for nicotine addiction, became available on the Romanian market in 2000 and was prescribed for at least 10 years in many stop-smoking clinics throughout the country [12], it was not mentioned at all in the sampled community pharmacies in Târgu Mures, Romania. The study did not investigate the reasons behind the pharmacists' preferences when advising quitters regarding pharmacological support, but based on a study performed on a sample of general practitioners in London, we may speculate that the total omission of bupropion from the pharmacists' advice might be related to the persisting doubts regarding the safety profile of the drug [11].

While dietary supplements designed to help smokers to quit were available in most pharmacies in a wide variety of preparations (tablets, capsules, syrups, powders, tinctures), only a small minority of pharmacists recommended them. This observation suggests that scientifically tested pharmacological products take priority over complementary and alternative remedies. Most pharmacists have provided correct explanations regarding how the recommended medication works but none of them referred to research as evidence of medication efficacy. The only type of evidence mentioned by a few pharmacists was anecdotal evidence based on the experience of successful quitters. While this type of evidence is highly persuasive and convenient to use during pharmacist-client interactions, it is considered the least reliable type of medical evidence. As expected, most of the pharmacists explained to the client how the medication should be taken, how often, and for how long a time. These data are in line with those reported by Rusu et al. [8]. On the other hand, only a few of them presented information regarding the medications' adverse effects and contraindications. The proportion of pharmacists giving information about adverse effects was much lower than reported by Rusu et al. [8]. This observation should raise a red flag regarding the completeness and balanced character of the pharmacists' advice, as these details are essential to assist smokers to reach an informed decision and promote responsible use of smoking cessation medication. The study methodology did not allow us to identify the reasons behind such vital omissions, possibly limited time, lack of training or low concern, but warrants further clarification in a future survey.

Although assessing the level of nicotine addiction is an important component of effective smoking cessation assistance, apparently, none of the pharmacists were 
FARMACIA, 2020, Vol. 68, 4

familiar with the Fagerstrom test and not many pharmacists inquired the client about withdrawal symptoms and their severity thus missing an opportunity to tailor the intervention to each particular case. Similarly, only a few pharmacists asked the smoker about previous quit attempts and their outcome.

The study suggests that about half of the pharmacists engaged in brief practical counselling regarding quit strategies and techniques but mostly upon request and rarely in a proactive manner. However, in almost half of the cases, the clients were not offered any such guidance. The suggested techniques included besides sound advice, some methods that were not necessarily evidence-based.

Referral of the interested smokers to cessation centres may represent the most important and applicable intervention even when pharmacists work under severe time constraints. The rate of referral observed in our survey was fairly high (approx. 70\%) although only about one in five pharmacists referred the clients proactively. Most smokers were advised to see a pulmonologist or a family practitioner but very few pharmacists seemed aware of the ongoing National Stop-Smoking Program. Besides the mostly positive observations, two disturbing findings should be noted: firstly, almost a third of the pharmacists suggested that a formal visit to a medical professional is not needed; secondly, in two instances, a clearly opposing attitude was expressed toward participation in a stopsmoking program. Exposing smokers to contradictory messages at their first contact with the medical professionals should be avoided as it may weaken their trust in offered assistance and reduce their engagement in the quit process.

This is the first study implementing the simulated client method to assess the availability of tobacco cessation products and services in community pharmacies in Romania. A similar investigation was conducted in a representative sample of 100 pharmacies located in the Sydney metropolitan area, Australia [9]. The authors reported that nicotine replacement products were dispensed as a single medication in $36 \%$ of the pharmacies. In another $6 \%$ of the locations, the products were offered in combination with other pharmaceutical products. Notably, nicotine replacement products were suggested but not supplied, pending a medical prescription, in $45 \%$ of the investigated pharmacies. Overall, the Australian authors conclude that the overall skills of the pharmacists in providing smoking cessation services were somewhat inadequate [9].

The study has a number of limitations. The results of the study may not be extrapolated to pharmacies outside Târgu Mureș since the sample was designed to be representative only for Târgu Mureş, Romania. In as much as interactions between the pharmacy personnel and patients are influenced by the demographic and medical profile of the latter, our study may primarily provide insights regarding stop-smoking services and products offered to relatively young costumers (20 - 25 years of age). Finally, since the encounters were not recorded some of the finer details may have been omitted. However, data were entered within five minutes after the completion of the evaluation.

\section{Conclusions}

Overall, pharmacists recommended at least one evidencebased medication and provided appropriate advice about the medicine (route, length and frequency of administration). Providing evidence regarding efficacy and warnings about adverse effects was largely omitted while guidance regarding quit techniques was of varying quality including questionable tips in some instances. The study identified strengths and weaknesses that will be useful in developing a training program aimed to promote a smoking cessation intervention in the community pharmacies in Târgu Mureș, Romania.

\section{Conflict of interest}

The authors declare no conflict of interest.

\section{References}

1. Agomo C, Udoh A, Kpokiri E, Osuku-Opio J, Community pharmacists' contribution to public health: assessing the global evidence base. Clinical Pharmacist, 2018; 10(4): 1-22.

2. Cahill K, Lindson-Hawley N, Thomas KH, Fanshawe TR, Lancaster T, Nicotine receptor partial agonists for smoking cessation. Cochrane Database Syst Rev., 2016; 5: CD006103: 1-172.

3. Cahill K, Stevens S, Perera R, Lancaster T, Pharmacological interventions for smoking cessation: an overview and network meta-analysis. Cochrane Database Syst Rev., 2013; 5: CD009329: 1-49.

4. Carson-Chahhoud KV, Livingstone-Banks J, Sharrad KJ, Kopsaftis Z, Brinn MP, To-A-Nan R, Bond CM, Community pharmacy personnel interventions for smoking cessation. Cochrane Database Syst Rev., 2019; 2019(10): CD003698.

5. Chirila M, Ghita I, Fulga I, Current knowledge on bupropion and varenicline clinical efficacy in nicotine dependence. Farmacia, 2015; 63(1): 1-7.

6. Fiore MC, Jaen CR, Baker TB, Treating Tobacco use and dependence. Clinical practice guideline 2008 update Rockville, MD: US Department of Health and Human Services. Public Health Service, 2008.

7. Odorico M, Le Goff D, Aerts N, Bastiaens H, Le Reste JY, How To Support Smoking Cessation In Primary Care And The Community: A Systematic Review Of Interventions For The Prevention Of Cardiovascular Diseases. Vasc Health Risk Manag., 2019; 15: 485-502.

8. Rusu A, Vari CE, Hancu G, Pasca MD, Botezatu R, Cucoranu D, Muntean DL, Brief assessment of pharmacist-patient communication efficiency in Romanian pharmacies. Farmacia, 2018; 66(6): 1091-1096.

9. Saba M, Diep J, Bittoun R, Saini B, Provision of smoking cessation services in Australian community 
pharmacies: a simulated patient study. Int J Clin Pharm., 2014; 36(3): 604-614.

10. Trofor L, Crisan-Dabija R, Cioroiu ME, Man ME, Cioroiu IB, Buculei I, Cernat RI, Stefanescu C, Trofor $\mathrm{AC}$, Evaluation of oxidative stress in smoking and nonsmoking patients diagnosed with anxious-depressive disorder. Farmacia, 2020; 68(1): 82-89.

11. Vogt F, Hall S, Marteau TM, General practitioners' beliefs about effectiveness and intentions to prescribe smoking cessation medications: qualitative and quantitative studies. BMC Public Health, 2006; 6: 277: 1-12.

12. $\mathrm{xxx}$ - Romanian Society of Pneumology, Guideline for smoking cessation and specialized smoking assistance (GREFA), $2^{\text {nd }}$ edition, TehnoPress Publishing House, Iaşi, 2010; 46-47, (available in Romanian).

13. xxx - World Health Organization, WHO Framework Convention on Tobacco Control, 2003. http://apps.who. int/iris/bitstream/10665/42811/1/9241591013.pdf?. 